\title{
Perancangan Model Pengukuran Kinerja Corporate Social Responsibility (CSR) di BPD Jatim
}

\author{
Wilda Khairin Najwah \\ Universitas Airlangga \\ e-mail: wildakhairin@gmail.com
}

\begin{abstract}
Companies that realize the importance of CSR do so to obtain a corporate image, this practice uses social activities for corporate marketing activities. Publication in the media is one of the mediums in obtaining a positive image for the company. BPD East Java has been carrying out CSR activities since 2007 but has a measuring tool such as a special KPI to measure the effectiveness of its CSR activities. So that the purpose of this research is to design a key performance indicator (KPI) of CSR activities at BPD East Java. This research uses a qualitative research method with a modified participation action research (PAR) approach or modified action research, which is carried out to obtain an overview of CSR activities in BPD East Java. Then the researchers made a measuring instrument or KPI to determine the effectiveness of CSR activities using the model: prism performance. The results of the KPI design are then discussed with relevant stakeholders for evaluation. The validation of the BPD East Java BPD CSR KPI is carried out by submitting the KPI design proposal to the company which is considered to understand the object of research with the company's real conditions and has a role in making corporate strategic decisions.
\end{abstract}

Keyword: key performance indicator (KPI), corporate social responsibility (CSR), performance prism

\section{PENDAHULUAN}

CSR (corporate social responsibility) di Indonesia menjadi sesuatu yang wajib dilakukan oleh perusahaan menurut Pasal 74 UU Nomor 40 Tahun 2007 tentang Perseroan Terbatas. Menurut ISO 26000, CSR tidak hanya donasi atau filantropi namun tanggung jawab perusahaan atas dampak dari operasi bisnisnya terhadap masyarakat dan lingkungan hidup secara transparan, beretika, serta berdampak kepada pembangunan berkelanjutan (Radyati, 2016).

Kegiatan corporate social responsibility (CSR) merupakan suatu bentuk nyata kepedulian kalangan dunia usaha terhadap lingkungan di sekitar usaha tersebut. Kegiatan CSR dapat dilakukan perusahaan pada berbagai bidang. Konsep CSR sebagai bentuk tanggung jawab perusahaan sudah dimulai sejak tahun 1970-an namun kegiatannya di Indonesia baru berkem- bang pesat pada dekade 2000-an. Pada saat ini diyakini pelaksanaan CSR adalah bagian dari pelaksanaan untuk mencapai status good corporate governance (GCG) oleh suatu perusahaan.

Perusahaan yang menyadari pentingnya CSR melakukannya untuk memperoleh corporate image, praktik ini menggunakan kegiatan sosial untuk kegiatan pemasaran perusahaan. Perkembangan dunia industri saat ini menuntut perusahaan tidak hanya menjual produk dan mendapat profit, namun perusahaan perlu meningkatkan corporate image untuk keberlanjutan perusahaannya, karena dengan image perusahaan yang positif maka akan meningkatkan kepercayaan konsumen maupun pemegang saham.

Salah satu upaya peningkatan corporate image yaitu melalui terlaksananya program CSR. $\mathrm{Pu}-$ blikasi di media menjadi salah satu medium dalam memperoleh image positif bagi perusahaan. 
BPD Jawa Timur merupakan salah satu perusahaan BUMD milik salah satu daerah di Indonesia dan telah melakukan kegiatan CSR sejak Tahun 2007. Namun, hingga saat ini BPD Jawa Timur belum memiliki KPI (key performance indicator) khusus yang digunakan untuk mengukur kegiatan CSR yang terealisasi selama ini. Oleh karena itu, peneliti merasa penting untuk mengevaluasi pelaksanaan program CSR pada BPD Jawa Timur agar dapat merancang key performance indicator (KPI) kegiatan CSR supaya terdapat standar baku dalam penerapan CSR di BPD Jatim.

\section{KERANGKA TEORETIS}

\section{Corporate Social Responsibility (CSR)}

Suatu perusahaan yang berdiri di suatu wilayah harus bertanggung jawab terhadap pemangku kepentingan (stakeholders) perusahaan yang bersangkutan. Stakeholders adalah orang atau kelompok yang dapat memengaruhi atau dipengaruhi oleh berbagai keputusan, kebijakan, maupun operasi perusahaan (Post, et al., 2002). Di dalam perusahaan Stakeholders terdiri dari inside dan outside stakeholders. Inside stakeholders terdiri dari pemegang saham (stockholders), para manajer dan karyawan. Sedangkan outside stakeholders terdiri dari pelanggan, pemasok, pemerintah, dan masyarakat.

Menurut The World Business Council for Sustainable Development, yaitu bahwa CSR merupakan suatu komitmen memberikan kontribusi bagi perkembangan ekonomi sambil meningkatkan kualitas hidup para pekerja dan keluarganya serta bagi komunitas lokal dan masyarakat pada umumnya. Definisi terakhir inilah yang diterima secara luas oleh praktisi dan aktivis CSR (Kalangit, 2009).
Regulasi CSR secara implisit dapat dilihat di UU No.23 Tahun 1997 tentang Pengelolaan Lingkungan Hidup; UU No. 8 Tahun 1999 tentang Perlindungan Konsumen; dan UU No. 13 Tahun 2003 tentang Ketenagakerjaan. Regulasi yang secara eksplisit mengatur CSR di antaranya adalah Undang-Undang No. 40 Tahun 2007 tentang Perseroan Terbatas (PT) tertanggal 16 Agustus 2007.

\section{Performance Prism}

Performance prism merupakan metode pengukuran yang mengalami perkembangan dari model sebelumnya, kelebihan yang dimiliki performance prism di antaranya dapat mengidentifikasi stakeholder dari berbagai kepentingan seperti karyawan, pemerintah, dan masyarakat. Sedangkan metode lain seperti contohnya balance scorecard, hanya dapat melihat dari dua sisi stakeholder yakni shareholder dan customer.

Pengukuran kinerja menggunakan model performance prism digambarkan dalam bangun prisma dengan lima perspektif, yaitu stakeholder satisfaction, strategy, process, capabilities, dan stakeholder contribution.

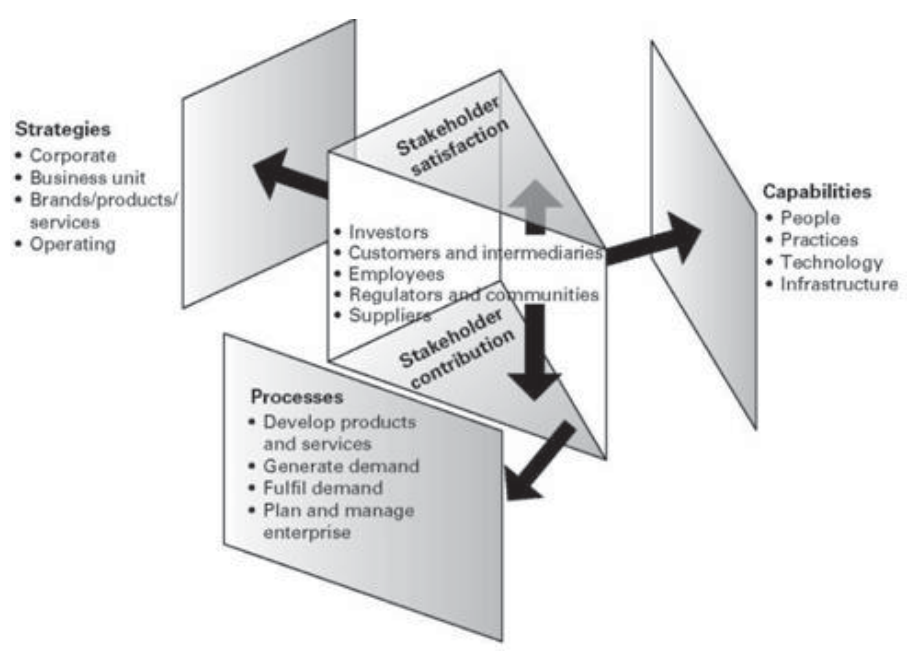

Gambar 1 Performance Prism

Sumber: Neely \& Adams, 2002 
Tahapan perancangan alat ukur/ key performance indicator (KPI) menggunakan model performance prism dijelaskan pada gambar berikut.

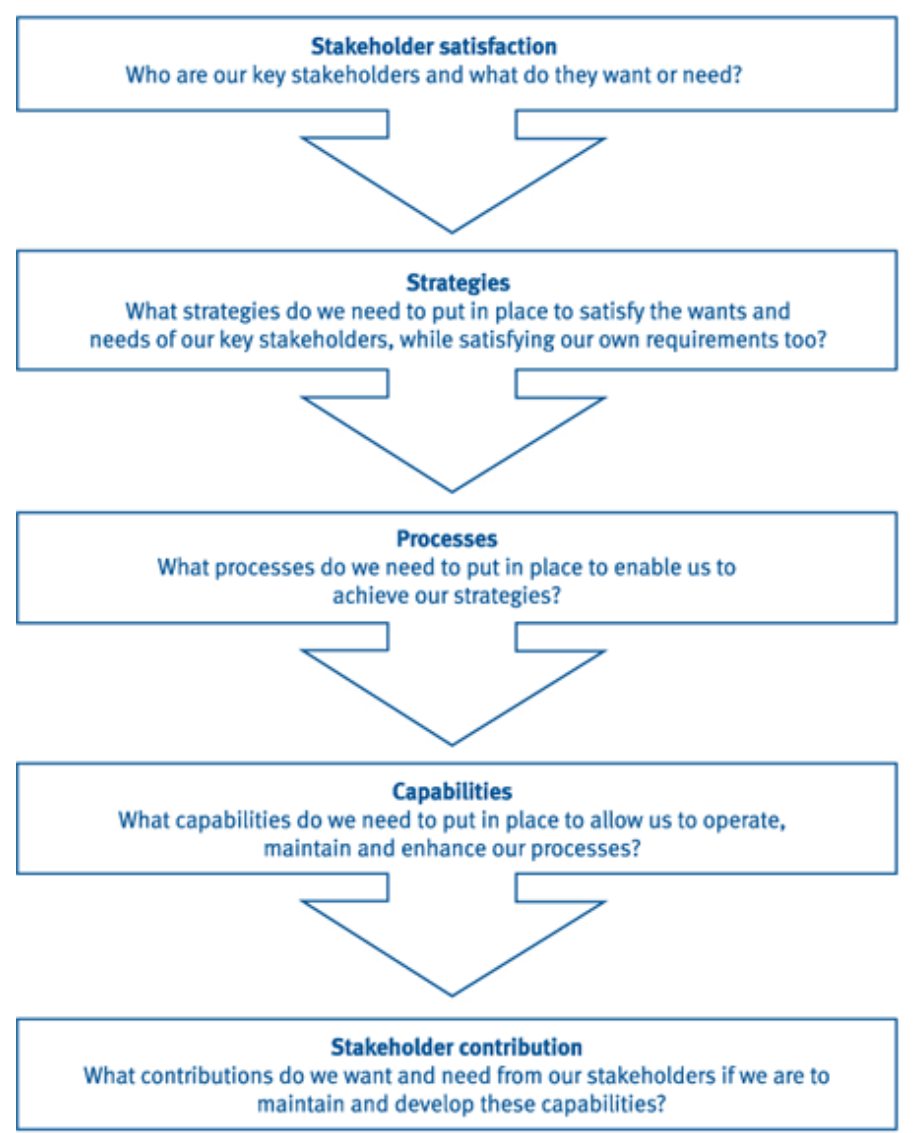

Gambar 2 Proses Perancangan Performance Prism Sumber: Kaplan, 2000

\section{ANALISIS DAN PEMBAHASAN}

Pendekatan penelitian yang digunakan dalam penelitian ini adalah pendekatan kualitatif. Moleong (2012) menyatakan bahwa metodologi kualitatif sebagai prosedur penelitian yang menghasilkan data deskriptif berupa kata-kata tertulis atau lisan dari orang-orang dan perilaku yang dapat diamati. Dalam penelitian ini digunakan metode kualitatif dengan desain deskriptif, yaitu penelitian yang memberi gambaran secara cermat mengenai individu atau kelompok tertentu tentang keadaan dan gejala yang terjadi (Koentjara- ningrat, 1993). Peneliti menggunakan metode kualitatif deskriptif untuk menganalisis data penelitian ini. Data yang diperoleh melalui wawancara dianalisis dengan menggunakan analisis deskriptif kualitatif yaitu dengan cara mendeskripsikan data yang diperoleh dari hasil wawancara dengan informan secara menyeluruh. Data wawancara dalam penelitian adalah sumber data utama yang menjadi bahan analisis data untuk menjawab masalah penelitian. Analisis data dilakukan dengan membuat suatu transkrip hasil wawancara dengan cara memutar kembali rekaman wawancara dan menuliskan kalimat yang sesuai dengan apa yang ada pada hasil wawancara tersebut. Setelah peneliti menuliskan hasil wawancara ke dalam bentuk transkrip, selanjutnya mereduksi data dengan cara abstraksi, yakni mengambil data yang sesuai dengan konteks penelitian dan mengabaikan data yang tidak diperlukan. Berdasarkan teknik analisis tersebut, maka diperoleh hasil penelitian sebagai berikut.

\section{Stakeholder Satisfaction}

Stakeholder yang terlibat secara langsung yaitu karyawan BPD pada corporate secretary khususnya di unit CSR, perwakilan dari forum CSR Bappeda Jawa Timur, dan masyarakat penerima bantuan program CSR.

Berikut ini adalah beberapa bagian dalam stakeholder satisfaction.

\section{Masyarakat}

Manfaat finansial, berdasarkan hasil penelitian di lapangan, manfaat yang diperoleh dari pelaksanaan kegiatan CSR ini adalah adanya peningkatan pendapatan.

Manfaat non-finansial, masyarakat penerima CSR juga merasakan manfaat lain seperti peningkatan kerapian, peningkatan kebersihan, peningkatan prestasi, dan peningkatan kesehatan. 


\section{Pemerintah}

Melalui wawancara narasumber yang mewakili pemerintah (Bappeda), program CSR memberikan satisfaction apabila mampu mewujudkan peningkatan kesejahteraan dan kemandirian masyarakat Jawa Timur secara berkelanjutan, memastikan program CSR di Jawa Timur berjalan dengan benar agar pelaksanaannya tidak tumpang tindih, dan program CSR perusahaan dapat selaras dengan program prioritas Pemprov Jatim.

Berdasarkan hasil penelitian kebutuhan dan keinginan (untuk mencapai satisfaction) perusahaan terhadap kegiatan CSR ini adalah mampu memenuhi penerapan prinsip good corporate governance (GCG). "Oleh karena CSR sendiri merupakan tata kelola perusahaan yang baik sehingga dapat memenuhi kebutuhan perusahaan. CSR dan GCG berjalan beriringan untuk meningkatkan keberlanjutan perusahaan" (V, karyawan BPD), kegiatan CSR bersifat sustainable (berkelanjutan). ..."Pengen nya seperti yang tadi seperti inisiatif itu benar-benar tepat sasaran kalau misal itu memang dibutuhkan dan memang bermanfaat untuk kedepannya dipakai secara terus-menerus"... (Sdri. V, karyawan BPD).

Pendapat Sdri. V juga didukung oleh Sdr. W, ... "Membantu perekonomian pemberdayaan pada UMKM dan pada keberlangsungannya... berkelanjutan"... (W, salah satu pejabat di unit CSR). Meningkatkan corporate image ... "Tujuannya cuma satu meningkatkan corporate image"... (Sdr. W, salah satu pejabat di unit CSR).

Memperoleh CSR Awards ..."Kita dapat award di forum ISDA"... (Sdri. E, karyawan BPD). Pernyataan Sdr. E didukung oleh Sdr. V sebagai berikut. "Program inisiatif (sanitasi) yang itu tadi sih yang menang karena sanitasi tadi karena dia juga sudah dapat dua penghargaan itu dari yang Jakarta itu ISDA (Indonesia Sustainable Development Award)" (Sdri. V, karyawan BPD).

\section{Strategies}

Penentuan strategi merupakan tahap kedua pada model performance prism, setelah menemukan stakeholder satisfaction. Strategi dibutuhkan oleh perusahaan untuk memenuhi keinginan dan kebutuhan stakeholder kunci sekaligus memenuhi kebutuhan perusahaan.

Strategi yang dibutuhkan BPD Jatim untuk memenuhi stakeholder satisfaction adalah penerapan prinsip good corporate governance (GCG), meningkatkan corporate image terkait penilaian positif dari masyarakat/awareness masyarakat terhadap CSR BPD Jatim, penerimaan awards, publikasi positif dari media.

\section{Processes}

Pada tahap proses, peneliti mendaftar proses yang diperlukan BPD Jatim untuk mencapai strategi-strategi dalam penerapan prinsip GCG dengan melakukan mekanisme self-assessment TATA (tata kelola) dengan cara PIC berwenang meng-input dan menganalisis berdasarkan data kuantitatif dan kualitatif dengan memperhatikan prinsip pada GCG, yaitu transparansi, akuntabilitas, responsibilitas, independensi, dan kewajaran mengajukan review pada otor 1 (pemimpin divisi terkait), jika ditolak PIC merevisi kembali hasil analisis dan apabila diterima, hasil analisis diteruskan ke otor 2 (Pemimpin Divisi Kepatuhan \& Tata Kelola), selanjutnya, laporan dicetak dan diajukan ke direksi untuk disampaikan ke OJK.

Langkah berikutnya ialah meningkatkan corporate image dengan cara mengikuti ajang CSR Awards, mengidentifikasi kegiatan awarding yang diadakan oleh penyelenggara, menyiapkan dan melengkapi persyaratan yang diminta penyelenggara, melihat tema yang diangkat serta atribut yang diminta oleh penyelenggara awarding, menyiapkan data-data dan resume program CSR yang sesuai dengan tema CSR Awards yang 
akan diikuti media, bekerja sama dengan PR perusahaan yang memiliki list media, menjalin hubungan baik dengan media partner, menginfokan kepada media atas program CSR perusahaan \& perolehan awards yang terkait dengan CSR, mengundang media dalam acara penyerahan CSR kepada masyarakat, memberikan kuesioner terhadap masyarakat yang memperoleh dampak kegiatan CSR, melakukan wawancara terhadap masyarakat penerima CSR, merangkum testimoni positif dari masyarakat untuk diangkat ke media sosial perusahaan, seperti: website, majalah, video company profile, dan lain-lain.

\section{Capabilities}

Untuk menjalankan proses, perusahaan perlu mengidentifikasikan kemampuan atau kapabilitas yang dimilikinya. Berdasarkan observasi dan wawancara dengan karyawan BPD Jatim, menurut peneliti berikut adalah kemampuan yang dimiliki oleh perusahaan untuk menjalankan proses di atas.

1. Jumlah kegiatan CSR yang meningkat dari tahun sebelumnya.

2. Jumlah anggaran CSR yang meningkat dari tahun sebelumnya.

3. Jumlah publikasi mengenai CSR.

4. Jumlah SDM yang berasal dari karyawan CSR di kantor pusat dan dibantu oleh karyawan pelaksana di kantor cabang.

\section{Stakeholder Contribution}

Selanjutnya peneliti perlu mengidentifikasi stakeholder contribution dari masing-masing pemangku kepentingan. Wawancara terhadap stakeholder kunci menghasilkan informasi terkait kontribusi pemangku kepentingan untuk mencapai satisfaction terhadap program CSR BPD Jatim.

Hasil dari wawancara dengan beberapa karyawan perusahaan, diketahui kontribusi mereka dalam terlaksananya program CSR adalah sebagai berikut.

1. Melakukan koordinasi dengan hadir pada pertemuan Forum CSR Bappeda.

2. Melakukan sinkronisasi antara program usulan dari Forum CSR Bappeda dengan program yang sesuai dengan bidang pada perusahaan.

3. Menyampaikan laporan program CSR pada RUPS.

4. Membuat analisis, usulan, dan pelaksanaan program CSR.

5. Merealisasikan program CSR untuk masyarakat.

6. Melakukan sosialisasi dan koordinasi dengan kantor cabang melalui surat, telepon, dan pertemuan secara langsung.

7. Mengevaluasi pelaksanaan program CSR.

Sedangkan kontribusi yang dilakukan oleh pemerintah berdasarkan hasil wawancara dengan pihak Bappeda adalah sebagai berikut.

1. Memetakan kondisi lapangan dan menentukan kebutuhan program CSR.

2. Mengoordinasikan hasil pemetaan dengan perusahaan agar pelaksanaan program CSR tidak tumpang tindih.

3. Membantu perusahaan dalam melakukan monitoring dan evaluasi.

4. Memberikan dukungan pada perusahaan dalam melaksanakan program CSR (rewards).

5. Mengadakan rapat koordinasi anggota Forum CSR Bappeda.

Hasil dari wawancara dengan narasumber yang mewakili masyarakat penerima bantuan untuk setiap bidang CSR yang ada di perusahaan adalah sebagai berikut.

1. Mengajukan permohonan CSR ke perusahaan.

2. Melengkapi dokumen permohonan sesuai dengan yang ditetapkan oleh perusahaan. 
3. Membantu perusahaan menggali permasalahan sosial untuk ide program CSR ke depan.

4. Memberikan bantuan tenaga untuk mendukung kesuksesan program CSR perusahaan.

\section{KESIMPULAN}

Perancangan KPI menggunakan model performance prism dilakukan untuk mengetahui kinerja CSR perusahaan sehingga dapat dilaporkan kepada seluruh stakeholder. Berdasarkan observasi yang dilakukan di lingkungan perusahaan, peneliti menentukan tiga stakeholder kunci pada pelaksanaan CSR di BPD Jatim yaitu karyawan perusahaan, pemerintah dan masyarakat. Kemudian, dari wawancara yang dilakukan peneliti mengidentifikasi keinginan dan kebutuhan (satisfaction) stakeholder dan kontribusinya untuk mencapai hal tersebut. Peneliti memetakan strategi, proses, dan kapabilitas dari masingmasing stakeholder kunci untuk mengetahui kontribusi lain yang dapat dilakukan. Peneliti mengintegrasikan hasil pemetaan sehingga diperoleh 12 indikator pengukuran CSR di BPD.

KPI CSR ini tidak dapat diterapkan pada perusahaan lain, karena perumusannya disesuaikan dengan kondisi yang ada di BPD Jatim, dan setiap perusahaan memiliki kondisi yang berbeda.

\section{DAFTAR RUJUKAN}

Aggraini, F. 2006. Pengungkapan informasi sosial dan faktor-faktor yang memengaruhi pengungkapan informasi sosial dalam laporan keuangan tahunan (Studi empiris pada perusahaan-perusahaan yang terdaftar bursa efek Jakarta), Simposium Nasional Akuntansi 9. Alexander GJ and Buchloz RA. 1978.

Ahmad, N., Maliah, \& Siswantoro, D. 2003. Corporate social responsibility disclosure in $\mathrm{Ma}$ - laysia: An Analysis of Annual Reports of KLSE Listed Companies, IIUM Journal of Economics and Management Malaysia 11 (1). The Intenational Islamic University Ambadar, J. 2008. CSR Dalam Praktik Di Indonesia: Wujud Kepedulian Dunia Usaha. Jakarta: Elex Media komputindo.

Aris. 2010. CSR bisa jadi pengurang pajak. (Online), (http://www.bisnis.com/articles/csrbisa-jadi-pengurang-pajak, diakses 17 Juli 2018)

Arista. 2011. Pengaruh Corporate Social Responsibility Terhadap Profitabilitas dan Kinerja Pasar Perusahaan (Studi Empiris pada Perusahaan LQ45 periode 2007-2008). Universitas Negeri Malang. Skripsi tidak diterbitkan.

Asongu, J.J. 2007. The history of Corporate Social Responsibility, Journal of Business and Public Police, Vol. 1, No. 2. Asongu, J.J. http://www.mallenbanker.net/csr?CSRfiles/ definition.html. Diakses, 17 Juli 2018.

Baron, D.P. 2006. Business and its Environment. Fifth edition. Upper Saddle River, New Jersey: Person-prantice Hall.

Burkett W., B \& Douglas G. 2016. "Voluntary Regulation of International Labour Standards: An Overview of the Corporate Social Responsibility Phenomenon" diakses dari http://library.findlaw.com/2012/Sep/11/ 246322.html mengutip "Corporate Social Responsibility: An IOE Approach.” International Oragization of Employers Position Paper, at p. 2, online: http:///www.uscib.org/ docs/03_21_03_CR.pdf.

Choi, D.Y. \& Grey, E.R. 2008. The Venture Development Processes of Sustainable Entrepreneurs. Management Research News, Vol. 31 No. 8.

Dafid, R.F. 2009. Manajemen Strategis. Jakarta: Salemba Empat. 
Dharmawan, A. 2011. Desa Model. Lembaga Pengabdian kepada Masyarakat Universitas Negeri Malang.

Djakfar, M. 2012. Etika Bisnis: Menangkap Spirit Ajaran Langit dan Pesan Moral Ajaran Bumi, Jakarta: Penebar Plus.

Efferin, S. \& Suherman, B. 2010. Seni Perang Sun $\mathrm{Zi}$ dan Sistem Pengendalian Manajemen. Jakarta: Elex Media Komputindo.

Erawati, E. 2010. Persoalan Hukum Seputar Tanggung Jawab Sosial dan Lingkungan Perseroan dalam Perundang-Undangan Ekonomi Indonesia. Direktorat Kementrian Hukum dan Hak Asasi Manusia. 23 Oktober 2018.

Gunadi. 2012. Bagaimana Perlakuan atas CSR? (Online), (http://www.businesslawyer.Ihslawfirm.com/2 ? id=Bagaimana-PerlakuanPajak-atas-CSR, diakses 18 September 2018).

Husted, B. 2003. "Governance Choices for Corporate Social Responsibility: To Contribute, Collaborate or Internalize?” Long Range Planning 36, No. 5 (2003), h.481-498.

Iqbal, N. 2012. "The Impact of Perceived Corporate Social Responsibility (CSR) on Job Attitude and Performance of Internal Stakeholders", International Journal of Human Resource Studies, Vol. 2, No. 4, pp. 77-86. Jefkins, F. \& Yadin, D. 2003. Public Relation, $5^{\text {th }}$ ed. Jakarta: Erlangga.

Kalangit, K.M. 2009. Konsep Corporate Social Responsibility, Pengaturan dan Pelaksanaannya di Indonesia.

Kartini. 2009. Corporate Social Responsibility Transformasi Konsep Sustainability Management dan Implementasi di Indonesia. Bandung: Refika Aditama.

Keputusan Menteri Keuangan No.:1232/KMK. 013/1989 tanggal 11 November 1989 tentang Pedoman Pembinaan Pengusaha Eko- nomi Lemah dan Koperasi melalui Badan Usaha Milik Negara.

Keputusan Menteri Keuangan No.:316/KMK016/1994 tanggal 27 Juni 1994 tentang Pedoman Pembinaan Usaha Kecil dan Koperasi melalui Pemanfaatan Dana dari Bagian Laba Badan Usaha Milik Negara.

Keputusan Menteri Negara BUMN No.: Kep236/MBU/2003 tentang Program Kemitraan BUMN dengan Usaha Kecil dan Program Bina Lingkungan.

Kotler. P. 1997. Marketing Management 6 Analysis, Planning, Implementation, and Control - Ninth Edition. New Jersey: PrenticeHall, Inc.

Moleong, L.J. 2010. Metodologi Penelitian Kualitatif, Cet. 21, Hlm. 248. Bandung: Rosdakarya.

Marshal, R.S. \& Harry, D.P. 2005. Introducing a new business course: "Global Business and Sustainability”. International journal of Sustainability in Higher Education, Vol. 6, No. 2.

Mas'ud \& Santoso. 2007. Survei Peran Corporate Social Responsibility (CSR) dan Harmonisasi Social Hubungan Industrial di Jawa Timur. BAPPENAS Jawa Timur.

McWilliam A. \& Siegel D. 2001. Corporate Social Responsibility: A Theory of the Firm Perspective. The Academy of Management Review, 26(1). ABI/INFORM Global.

Miles, B.M \& Huberman, M. 1992. Analisis Data Kualitatif Buku Sumber tentang MetodeMetode Baru. Jakarta.

Pearce, J.A. \& Robinson, R.B. 2007. Management Strategic: Formulation, Implementation, and Control, 10th Ed. McGraw-Hill Companies, Inc.

Peraturan Daerah Provinsi Jawa Timur Nomor 4 Tahun 2011 tentang Tanggung Jawab Sosial Perusahaan. 
Peraturan Menteri Negara BUMN No.: Per-O5/ MBU/2007 tanggal 27 April 2007 tentang Program Kemitraan BUMN dengan Usaha Kecil dan Program Binaan Lingkungan.

Peraturan Pemerintah Nomor 32 Tahun 1998 tentang Pembinaan dan Pengembangan Usaha Kecil.

Peraturan Pemerintah Nomor 93 Tahun 2010 tentang Sumbangan Penanggulangan Bencana Nasional, Sumbangan Penelitian dan Pengembangan, Sumbangan Fasilitas Pendidikan, Sumbangan Pembinaan Olahraga, dan Biaya Pembangunan Infrastruktur Sosial yang Dapat Dikurangkan dari Penghasilan Bruto.

Post, E., Lawrence, T.A., \& Weber. 2002. Business and Society: Corporate Strategy, Public Policy, Ethics. $10^{\text {th }}$ Ed. McGraw Hill Companies, Inc.

Prayogo, D. 2011. Evaluasi Program Corporate Social Responsibility dan Community Development pada Industri Tambang dan Migas Makara. Sosial Humaniora Vol. 15 No. 1.

Prayogo, D., \& Hilarius, Y. (2012). Efektivitas Program CSR/CD dalam Pengentasan Kemiskinan: Studi Peran Perusahaan Geotermal di Jawa Barat. Jurnal Sosiologi Masyarakat, Vol. 17, No. 1, 1-22.

Ricardo, S. 2013. Tanggung Jawab Direksi dalam Menjalankan Csr (Corporate Social Responsibility) Berdasarkan Peraturan Pemerintah Nomor 47 Tahun 2012. Transparency, II(2).

Robbins, S.P. \& Boulter, M. 2003. Management. Upper Saddle River, New Jersey: Prentice Hall.

Siswoyo, B.B. et al. 2010. Pemetaan Program Corporate Social Responsibility (CSR)-Kemi- traan Bina Lingkungan (PKBL) di Jawa Timur. Kerjasama Bappeda Provinsi Jawa Timur dan Fakultas Ekonomi Universitas Negeri Malang.

Soemirat, S. dan Elvinaro, A. 2003. Dasar-Dasar Public Relation, Bandung: Remaja Rosdakarya.

Solihin, I. 2011. Corporate Social Responsibility: From Charity to Sustainability. Jakarta: Salemba.

Suharto, E. 2007. Pekerjaan Sosial di Dunia Industri: Memperkuat Tanggung Jawab Sosial Perusahaan, Bandung: Refika Aditama.

Sulaiman, M. \& Zakaria, A. 2010. Jejak Bisnis Rasul. Jakarta: Hikmah (Mizan Publika).

Sugiyono. 2016. Metodologi Penelitian Kuantitatif, Kualitatif, dan RひD. Bandung: Alfabeta.

Undang-Undang Nomor 40 Tahun 2007 tentang Perseroan Terbatas.

Undang-Undang Nomor 19 Tahun 2003 tentang BUMN.

Undang-Undang Nomor 20 Tahun 2008 tentang UMKM.

Undang-Undang Nomor 25 Tahun 2007 tentang Penanaman Modal.

Undang-Undang Nomor 40 Tahun 2007 tentang Perseroan Terbatas.

Undang-Undang RI Nomor 36 Tahun 2008 tentang Perubahan Keempat atas UndangUndang Nomor 7 Tahun 1983 tentang Pajak Penghasilan.

Virvilaite, R. \& Ugne D. 2011. "Corporate Social Responsibility in Forming Corporate Image". Inzinerine Ekonomika-Engineering Economics, 22(5), 534-543.

Watrick, L., Cochran, \& L. Phillip. 1985. The Evolution of the Corporate Social Performance Model. The Academy of Management Review, Vol. 10, No. 4, October. 